\section{Clinical implication of}

stimulation-induced

dyskinaesia in globus pallidus

deep brain stimulation for

advanced Parkinson's disease

\section{INTRODUCTION}

Deep brain stimulation (DBS) has been proven effective in improving motor symptoms and reducing levodopa-induced dyskinaesia (LID) of advanced Parkinson's disease (PD). DBS for PD targets either the subthalamic nucleus (STN) or the globus pallidus interna (GPi). The therapeutic effects on motor symptoms are similar between STN and GPi DBS. ${ }^{1}$ However, it has been reported that GPi DBS is more effective in improving LID. Thus, GPi DBS may be preferred in patients with severe LID. ${ }^{1}$

Stimulation-induced dyskinaesia (SID) can be observed in patients who undergo DBS. SID in patients with PD who undergo STN DBS may indicate proper positioning of the lead, and is considered to be a good prognostic factor for motor outcome. ${ }^{2}$ SID may also develop in GPi DBS, and dorsal GPi or globus pallidus externa (GPe) stimulation in particular may be associated with SID. ${ }^{3}$ However, little is known about the clinical implications of SID in GPi DBS. Therefore, the aim of this study was to investigate the effect of SID on the clinical outcomes of GPi DBS.

\section{METHODS}

Subjects

We retrospectively reviewed the electronic medical records of 60 patients with PD who received bilateral GPi DBS between January 2015 and February 2019 at the Departments of Neurology and Neurosurgery at Asan Medical Center, Seoul, Korea. Stereotactic implantation of DBS electrodes 3387 (Medtronics, Minnepolis, Minnesota, USA) was performed. Eight patients $(13.3 \%)$ who showed SID at initial programming were identified, and 15 matched controls who did not show SID were selected for comparison. All subjects were evaluated by Unified Parkinson's Disease Rating Scale (UPDRS) at preoperative baseline and 12 months after surgery.

Electrode localisation and the volume of tissue activated (VTA) estimation

The Lead-DBS MATLAB toolbox was employed to visualise the location of the contacts in the globus pallidus (online supplemental figure 1; www.lead-dbs.org, V.2.1.6). ${ }^{4}$ VTA estimation was conducted based on patient's optimised stimulation parameters at the initial programming session. Detailed methods are described in the online supplemental methods.

\section{Statistical analysis}

The baseline demographic and clinical data were analysed using Student's t-test or Mann-Whitney $U$ test for continuous variables and Fisher's exact test for categorical variables. Wilcoxon signed rank test was used to compare the preoperative and postoperative UPDRS III scores. Intersections between VTA and the GPi motor nucleus volume were correlated with the stimulation effect by conducting Spearman's rank correlation using the Lead-DBS toolbox. With the exception of the correlation of VTA and the stimulation effect, all data were analysed using IBM SPSS V.22.0, and the significance level was $\mathrm{p}<0.05$.

\section{RESULTS}

SID was present in 2 of 32 men (6.3\%) and 6 of 28 women $(21.4 \%)$ at initial programming. Although a higher percentage of female patients developed SID than male patients, the difference was not statistically significant $(p=0.130)$. There were no significant differences in the baseline between patients with PD with SID and those without (online supplemental table 1). SID occurred in the dorsal lead above contact 2, except for one patient, in whom dyskinaesia occurred at contacts 1 and 2 . Three patients with PD developed dyskinaesia bilaterally (online supplemental table 2).

There were no significant differences in UPDRS III scores between the two groups at 12 months after surgery. However, the stimulation effect calculated by comparing UPDRS III scores of the stimulation on/ off state in the medication off state was significantly smaller in patients with PD with SID than in those without (table 1A, $4.18 \pm 3.18$ vs $9.33 \pm 4.77, p=0.013$ ). The difference in UPDRS III scores in off state before and after DBS was higher in patients with SID than in those without, but it was not significant (online Supplemental table $3,4.94 \pm 17.97$ vs $1.63 \pm 14.62$, $\mathrm{p}=0.638$ ). After initial programming, the mean voltages were $2.18 \pm 0.39$ in patients with PD with SID, and $2.77 \pm 0.47$ in those without (table $1 \mathrm{~B}, \mathrm{p}=0.001$ ). There were no significant differences in the distance between the ventral or active contact and
GPi motor nucleus of the two groups (table 1B). Of all patients with PD, none showed SID on stimulation at 12 months after surgery.

Contact 2 of the two groups was located on the dorsal GPi or GPe (online supplemental figure 2). The stimulation effect was positively correlated with the volume of intersections between the VTA and GPi motor nucleus (online supplemental figure $3 \mathrm{~A}, \mathrm{r}=0.42, \mathrm{p}=0.025)$. The mean VTA of patients with PD with SID was lower compared with those without, but it did not reach statistical significance (online supplementary figure 3B, $60.60 \pm 46.92$ vs $96.21 \pm 52.96, p=0.169)$.

\section{DISCUSSION}

Patients with PD with GPi DBS-induced SID showed a smaller stimulation effect than those without SID, but there were no significant differences in UPDRS III scores between the two groups at 12 months after surgery. The voltage of stimulation after initial programming was significantly lower in patients with PD with SID compared with those without. The dorsal lead of patients with PD with and without SID is located in the dorsal GPi or GPe.

GPi DBS has a direct antidyskinetic effect, and may be considered as a target for advanced patients with PD with LID. ${ }^{1}$ However, the clinical impact of dyskinaesia appearing by GPi stimulation is not well known. In previous studies, stimulation of the dorsal GPi or GPe has been shown to improve akinaesia, but SID may occur. Conversely, stimulation of ventral GPi can suppress SID but hypokinaesia may worsen. ${ }^{35}$ If SID appears after DBS surgery, it may be limited to adjusting programming parameters and selecting simulation contacts. Our results indicate that these obstacles in the programming strategy may affect the optimisation of the VTA and stimulation effect of GPi DBS.

Our study has several limitations. First, the limited numbers of patients and retrospective design could affect statistical power. Second, the model-based electrode reconstruction using Lead-DBS cannot exclude the possibility of error, and the VTA modelling does not represent the real bioelectrical effects of DBS. ${ }^{4}$

\section{CONCLUSION}

Our results suggests that patients with PD with GPi DBS-induced SID had different stimulation effect and programming parameters compared with those without, although no significant difference in the overall motor outcome was observed. 
Table 1 Clinical outcomes 12 months after globus pallidus deep brain stimulation in patients with Parkinson's disease (PD) (A). Programming parameters and distance from electrode contacts to globus pallidus motor nucleus (B)

\begin{tabular}{|c|c|c|c|}
\hline & $\begin{array}{l}\text { Patients with PD with SID } \\
(n=8)\end{array}$ & $\begin{array}{l}\text { Patients with PD without SID } \\
(n=15)\end{array}$ & $P$ value \\
\hline \multicolumn{4}{|l|}{ (A) } \\
\hline UPDRS III (medication off, stimulation on) & $33.50 \pm 12.87$ & $32.13 \pm 7.91$ & 0.925 \\
\hline UPDRS III (medication off, stimulation off) & $37.68 \pm 14.89$ & $41.46 \pm 8.39$ & 0.441 \\
\hline UPDRS III (medication on, stimulation on) & $20.68 \pm 14.09$ & $15.23 \pm 8.88$ & 0.266 \\
\hline UPDRS III (medication on, stimulation off) & $26.00 \pm 15.56$ & $22.13 \pm 12.87$ & 0.728 \\
\hline UPDRS IV (medication off, stimulation on) & $6.37 \pm 3.62$ & $6.80 \pm 2.75$ & 0.681 \\
\hline Stimulation effect in medication off state & $4.18 \pm 3.18$ & $9.33 \pm 4.77$ & 0.013 \\
\hline Stimulation effect in medication on state & $5.31 \pm 10.81$ & $6.90 \pm 6.00$ & 0.115 \\
\hline $\operatorname{LEDD}(\mathrm{mg})$ & $1373.25 \pm 463.10$ & $1272.86 \pm 322.19$ & 0.548 \\
\hline \multicolumn{4}{|l|}{ (B) } \\
\hline \multicolumn{4}{|l|}{ At initial programming } \\
\hline Voltage (V) & $2.18 \pm 0.39$ & $2.77 \pm 0.47$ & 0.001 \\
\hline Parameter configuration & All monopolar & All monopolar & \\
\hline \multicolumn{4}{|l|}{ At 12 months programming } \\
\hline Voltage (V) & $2.58 \pm 0.90$ & $3.07 \pm 0.67$ & 0.116 \\
\hline Parameter configuration & Bipolar 3, monopolar 6, interleaving 1 & Bipolar 2, monopolar 28 & \\
\hline Ventral contact to GPi motor nucleus ( $\mathrm{mm}$ ) & $1.87 \pm 1.31$ & $1.48 \pm 1.11$ & 0.287 \\
\hline Active contact to GPi motor nucleus (mm) & $2.50 \pm 1.29$ & $1.94 \pm 1.54$ & 0.287 \\
\hline
\end{tabular}

Data are represented as mean \pm SD.

Results in bold letters indicate significant difference between groups $(p<0.05)$.

GPi, globus pallidus interna; LEDD, Levodopa equivalent daily dose; SID, stimulus-induced dyskinaesia; UPDRS, Unified Parkinson's Disease Rating Scale.;

Seung Hyun Lee, ${ }^{1}$ Mi Sun Kim, ${ }^{2}$ Yun Su Hwang, ${ }^{1}$ Sungyang Jo, ${ }^{1}$ Kye Won Park, ${ }^{1}$ Sang Ryong Jeon, ${ }^{3}$ Sun Ju Chung ${ }^{1}$

'Department of Neurology, Asan Medical Center, University of Ulsan College of Medicine, Songpa-gu, Seoul, The Republic of Korea

${ }^{2}$ Department of Neurology, Asan Medical Center, Songpa-gu, Seoul, The Republic of Korea ${ }^{3}$ Department of Neurosurgery, Asan Medical Center, University of Ulsan College of Medicine, Songpa-gu, Seoul, The Republic of Korea

Correspondence to Dr Sun Ju Chung, Department of Neurology, Asan Medical Center, University of Ulsan College of Medicine, Songpa-gu, Seoul, The Republic of Korea; sjchung@amc.seoul.kr

Contributors SHL and SJC contributed to the conception and design of this study. All author acquired and analysed the data. SHL, KWP, SYJ and SJC drafted manuscript. All authors have read and approved the final version of the manuscript.

Funding This study was supported by a grant from the Korea Healthcare Technology R\&D Project, Ministry of Health \& Welfare, Republic of Korea (HI19C0256).

Competing interests None declared.

Patient consent for publication Not required.

Provenance and peer review Not commissioned; externally peer reviewed.

Supplemental material This content has been supplied by the author(s). It has not been vetted by BMJ Publishing Group Limited (BMJ) and may not have been peer-reviewed. Any opinions or recommendations discussed are solely those of the author(s) and are not endorsed by BMJ. BMJ disclaims all liability and responsibility arising from any reliance placed on the content. Where the content includes any translated material, BMJ does not warrant the accuracy and reliability of the translations (including but not limited to local regulations, clinical guidelines, terminology, drug names and drug dosages), and is not responsible for any error and/or omissions arising from translation and adaptation or otherwise.

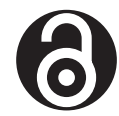

\section{OPEN ACCESS}

Open access This is an open access article distributed in accordance with the Creative Commons Attribution Non Commercial (CC BY-NC 4.0) license, which permits others to distribute, remix, adapt, build upon this work non-commercially, and license their derivative works on different terms, provided the original work is properly cited, appropriate credit is given, any changes made indicated, and the use is non-commercial. See: http:// creativecommons.org/licenses/by-nc/4.0/.

(C) Author(s) (or their employer(s)) 2021. Re-use permitted under CC BY-NC. No commercial re-use. See rights and permissions. Published by BMJ.

- Additional supplemental material is published online only. To view, please visit the journal online (http://dx.doi.org/10.1136/jnnp-2020-326015).

\section{Check for updates}

To cite Lee SH, Kim MS, Hwang YS, et al. J Neurol Neurosurg Psychiatry Epub ahead of print: [please include Day Month Year]. doi:10.1136/jnnp-2020326015

Received 30 December 2020

Accepted 20 June 2021

J Neurol Neurosurg Psychiatry 2021;0:1-2.

doi:10.1136/jnnp-2020-326015

\section{ORCID iD}

Sun Ju Chung http://orcid.org/0000-0003-4118-8233

\section{REFERENCES}

1 Okun MS, Foote KD. Subthalamic nucleus vs globus pallidus interna deep brain stimulation, the rematch: will pallidal deep brain stimulation make a triumphant return? Arch Neurol 2005;62:533-6.

2 Baizabal-Carvallo JF, Jankovic J. Movement disorders induced by deep brain stimulation. Parkinsonism Relat Disord 2016;25:1-9.

3 Krack P, Pollak P, Limousin P, et al. Opposite motor effects of pallidal stimulation in Parkinson's disease. Ann Neurol 1998:43:180-92.

4 Treu S, Strange B, Oxenford S, et al. Deep brain stimulation: imaging on a group level. Neuroimage 2020;219:117018.

5 Yelnik J, Damier P, Bejjani BP, et al. Functional mapping of the human globus pallidus: contrasting effect of stimulation in the internal and external pallidum in Parkinson's disease. Neuroscience 2000;101:77-87. 